\title{
Images in Anesthesia: Echo contrast as an adjunct to intraoperative angiography in the detection of endoleaks
}

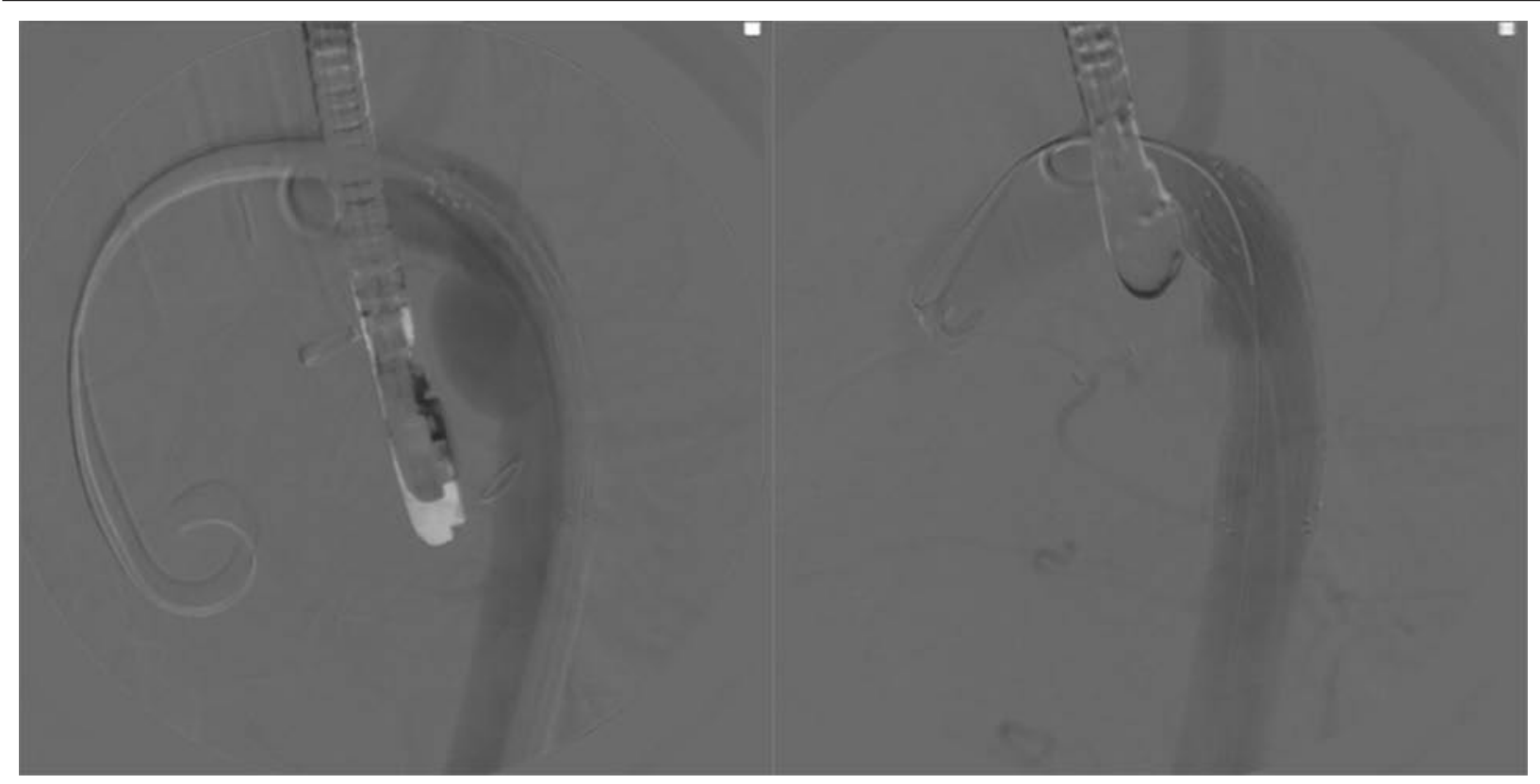

FIGURE 1 A) Angiogram demonstrating pseudo-aneurysm; B) Angiogram following endograft deployment, with no evidence of an endoleak.

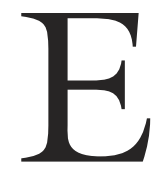

NDOVASCULAR repair is becoming the preferred management of traumatic disruption, dissection and aneurysmal disease of the thoracic aorta. Identifying and managing endoleaks is critical for the technical success of these reconstructions. Intraoperative transesophageal echocardiographic (TEE) examination of the endovascular stent provides a sensitive and safe means of detecting endoleaks, with a published algorithm outlining a systematic approach. ${ }^{1}$

Colour Doppler interrogation of the stent is used to identify possible endoleaks. Quantification of the velocity within the endoleak using pulse wave Doppler helps to discriminate true leaks from "porosity", with a minimum peak velocity of 50 $\mathrm{cm} \cdot \mathrm{sec}^{-1}$ as the suggested cut-off. Difficulties may arise when there is an obvious endoleak demonstrated with TEE that cannot be seen on angiography.
In this case, the post-traumatic disruption of the descending aorta was repaired with an endovascular stent. Following stent deployment there was no demonstrable endoleak on angiography (Figure 1) but a significant leak was detected using TEE (Figure 2; colour images and video imaging are available as Additional Material at: www.cja-jca.org). An infusion of echo-contrast (definity) resulted in opacification of the pseudo-aneurysm (Figure 2). The appearance of echo contrast outside the lumen of the endovascular stent confirmed the presence of a true endoleak ${ }^{2}$ that required further intervention. Balloon inflation at the site of the endoleak resulted in a complete seal. 


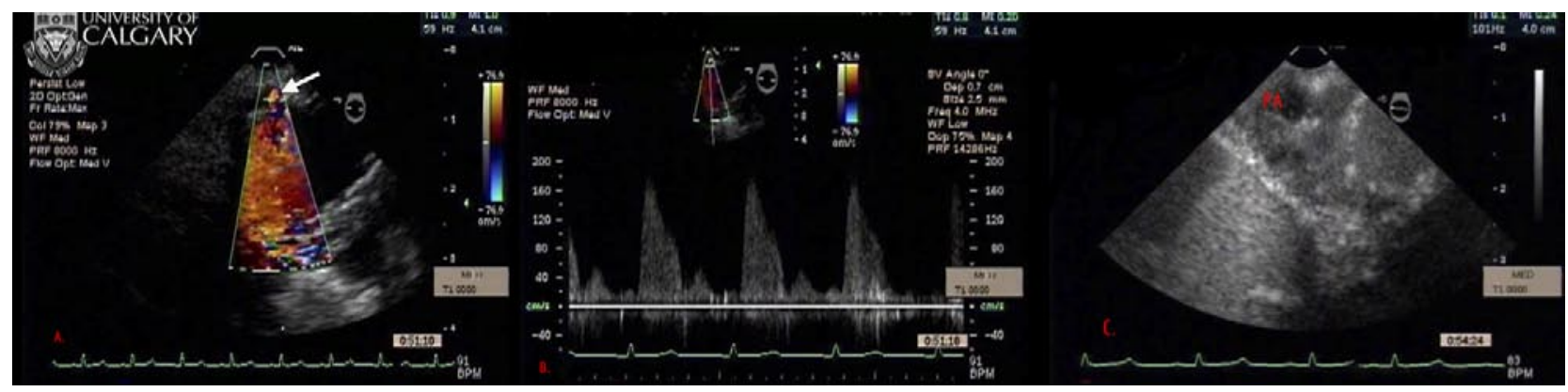

FIGURE 2 A) Colour Doppler imaging of the endograft demonstrating an endoleak (arrow); B) Pulse wave Doppler of endoleak; C) Echo contrast opacifying the lumen of pseudo-aneurysm confirming endoleak. Colour images are available as Additional Material at: www:cja-jca.org.

Gary Dobson FRCPC

Neal Maher FRCPC

Michelle Ball RDCS

Albert Kryski FRCPC

Randy Moore FRCSC

Peter Lougheed Centre, University of Calgary,

Calgary, Canada

E-mail: gary.dobson@calgaryhealthregion.ca

Accepted for publication February 2, 2006.

\section{References}

1 Rocchi G, Lofiego C, Biagini E, et al. Transesophageal echocardiography-guided algorithm for stent-graft implantation in aortic dissection. J Vasc Surg 2004; 40: $880-5$.

2 Heilberger P, Schunn C, Ritter W, Weber S, Raithel $D$. Postoperative color flow duplex scanning in aortic endografting. J Endovasc Surg 1997; 4: 262-71. 